\title{
¿Queréis revolución? Hacedla primero en vuestras almas (o en vuestros reglamentos). Anotaciones sobre posibles reformas reglamentarias al sistema arbitral ecuatoriano ${ }^{* * *}$
}

\author{
José Meythaler Baquero*** \\ Mateo Ruales Espinosa**** \\ Recibido/Received: 08/08/2018 \\ Aceptado/Accepted: 09/08/2018
}

Sumario: 1. Introducción. 2. Reforma a la LAM desde la óptica del sesgo de retrospectiva. 3. Reformas reglamentarias al sistema arbitral ecuatoriano. 3.1 Mecanismos de designación del Tribunal Arbitral. 3.2 Caución. 3.3 Árbitro de emergencia. 3.4 Recusación y excusa. 3.5 Otras consideraciones. 3.5.1 Prác-

* Los autores desean agradecer a Ana Paula Chávez Sanz por el apoyo brindado en la investigación de los reglamentos analizados.

** El presente artículo se publicó también en el libro Experiencias y Retos del Ecuador en el Arbitraje de Inversión y Comercial de la Cámara de Comercio Internacional.

*** Socio Principal de la firma Meythaler \& Zambrano Abogados. Profesor de la Pontificia Universidad Católica del Ecuador en las cátedras de Elementos de Ciencia Política y Derecho Administrativo; Universidad Central de Quito en la cátedra de Derecho de Empresas; y Universidad Internacional SEK en la cátedra de Ciencia del Estado; así como la Facultad de Administración de Empresas de la Universidad Central del Ecuador, en la cátedra de Introducción al Derecho. Doctor en Jurisprudencia, Abogado de los Tribunales de la República y Licenciado en Ciencias Jurídicas por la Pontificia Universidad Católica del Ecuador. Correo electrónico: jmeythaler@1mzabogados.com

**** Jefe del Área de Litigio Arbitral de la firma Meythaler \& Zambrano Abogados. Maestrante en la Maestría de Derecho Procesal y Litigación Oral de la Universidad Internacional SEK. Diplomatura en Arbitraje Comercial Internacional y de Inversión por la Comisión Interamericana de Arbitraje Comercial CIAC y la Cámara de Comercio de Lima. Abogado por la Universidad de los Hemisferios. Correo electrónico: mruales@1mzabogados.com

J. Meythaler y M. Ruales, “¿Quereís revolución? Hacedla primero en vuestras almas (o en vuestros reglamentos). Anotaciones sobre posibles reformas reglamentarias al sistema arbitral ecuatoriano", Revista Ecuatoriana de Arbitraje, No. 9, 2017. 
¿Queréis revolución? Hacedla primero en vuestras almas (o en vuestros reglamentos).

Anotaciones sobre posibles reformas reglamentarias al sistema arbitral ecuatoriano

ticas probatorias. 3.5.2 Calendario procesal. 3.5.3 Citación por la prensa. 3.5.4 Renuncia a la audiencia de lectura del laudo. 4. Conclusiones.

Palabras Clave: arbitraje, reforma a la Ley de Arbitraje y Mediación, reformas reglamentarias, buenas prácticas arbitrales, comparación de reglamentos.

KEYWORDS: arbitration, reform of the Arbitration and Mediation Law, regulatory reforms, good arbitration practices, comparison of arbitration rules.

RESUMEN: El presente artículo pretende realizar un análisis práctico sobre posibles reformas reglamentarias que podrían mejorar considerablemente la práctica arbitral nacional, mismas que pueden ser implementadas independientemente de que exista o no una reforma a la Ley de Arbitraje y Mediación. Primeramente, analizaremos la Ley de Arbitraje y Mediación desde la óptica del sesgo de retrospectiva para posteriormente aterrizar en un análisis comparativo de los reglamentos de los principales centros de arbitraje ecuatorianos. Dicho análisis, se lo realizará de forma pormenorizada y comparativa en las cuestiones relativas a (i) los mecanismos de designación del tribunal arbitral; (ii) la caución; (iii) la implementación del árbitro de emergencia; (iv) la inclusión de buenas prácticas probatorias internacionales; (v) la elaboración de un calendario procesal; (vi) la renuncia a audiencias irrelevantes como la de lectura de laudo, entre otros temas; planteando en cada una de ellas, lo que a criterio de los autores, son las mejores prácticas recogidas en los reglamentos analizados.

Abstract: This article pretends to make a practical analysis about possible regulatory arbitration reforms which could improve considerably the national arbitration practice, and could be implemented regardless the reform of the Arbitration and Mediation Law. First of all, we will analyze the Arbitration and Mediation Law from the perspective of the retrospective bias, in order to later land on a comparative 
analysis of the regulations of the main arbitration centers in Ecuador. This analysis will be made in detail while comparising issues about (i) the designation mechanisms of the tribunal; (ii) caution; (iii) the implementation of the emergency arbitrator; (iv) the inclusion of good international evidenciary practices; (v) the elaboration of a procedural calendar; (vi) the resignation to irrelevant audiences, like the one for the reading of the award; and other topics; proposing in each one of them, according to the authors, which are the best practices compiled in these analyzed arbitration regulations.

\section{INTRODUCCIÓN}

Con la reciente promulgación de la Ley de Arbitraje Comercial Internacional, Argentina se suma a los 5 países latinoamericanos, y a los más de 92 países a nivel mundial, en acoger la Ley Modelo realizada por la Comisión de las Naciones Unidas para el Derecho Mercantil Internacional (CNUDMI) ${ }^{1}$.

En el Ecuador, la reforma a la Ley de Arbitraje y Mediación (en adelante, LAM) fue un tema que, por múltiples motivos, se mantuvo en la congeladora por más de diez años. Sin embargo, actualmente ha vuelto a tomar relevancia en el foro arbitral, reavivando las críticas y cuestionamientos a dicho cuerpo normativo y reclamando la necesidad de una reforma. Esta crítica, sin lugar a dudas, se encuentra sometida al sesgo de retrospectiva, toda vez que nos encontramos realizando un juicio ex post; y es por ello que en la primera parte del ensayo realizaremos una aproximación a la luz del referido sesgo de las críticas a la norma arbitral ecuatoriana.

Por otra parte, estamos conscientes que una reforma a la LAM puede ser beneficiosa y necesaria; sin embargo, esta debe

1. Comisión de las Naciones Unidas para el Derecho Mercantil Internacional (CNUDMI). Situación actual: Ley Modelo de la CNUDMI sobre Arbitraje Comercial Internacional, 1985, con enmiendas adoptadas en 2006, <http://www.uncitral.org/uncitral/es/uncitral_texts/arbitration/1985Model_arbitration_ status.html> 
¿Queréis revolución? Hacedla primero en vuestras almas (o en vuestros reglamentos).

Anotaciones sobre posibles reformas reglamentarias al sistema arbitral ecuatoriano

iniciarse al interno del foro arbitral a través de la actualización de reglamentos y la sofisticación de las cláusulas arbitrales.

Para la presente investigación se ha realizado un análisis comparativo de los reglamentos de los principales centros de arbitraje a nivel nacional, esto es los Centros de Arbitraje y Mediación de la Cámara de Comercio de Quito (en adelante, CCQ), Cámara de Comercio Ecuatoriano-Americana (en adelante, AMCHAM), Cámara de Comercio de Guayaquil (en adelante, CCG), Cámara de la Construcción (en adelante, CENAMACO), Cámara de la Producción del Azuay (en adelante, CPA), Centro Internacional de Arbitraje y Mediación (en adelante, CIAM) y el Reglamento Modelo de Arbitraje Doméstico del Instituto Ecuatoriano de Arbitraje (en adelante, IEA); con la finalidad de rescatar las buenas prácticas contenidas en los mismos que pueden servir como luces para eventuales reformas.

\section{REForMA A LA LAM DESDE LA ÓPTICA DEL SESGO DE RETROSPECTIVA}

En el estudio realizado por KAMIN y RACHLINSKI ${ }^{2}$, basado en el caso Petition of Kisman Transit Co. ${ }^{3}$, los autores entrevistaron a 76 estudiantes de pregrado de derecho en la Universidad de Stanford. Para la elaboración del estudio se separaron dos grupos, uno de control y uno variable. La información entregada al grupo de control fue la siguiente:

- Una ciudad construyó un puente.

- El grupo debe determinar si el riesgo de inundación justifica contratar a un operador del puente como medida de precaución con el fin de que realice el monitoreo de las condiciones climáticas, para que levante el puente en caso de amenaza.

2. K. A. Kamin y J. J. Rachlinski, Ex Post $\neq$ Ex Ante: Determining Liability in Hindsight, Cornell Law Faculty Publications, 1995, <https://scholarship.law.cornell.edu/facpub/646/>.

3. Petition of Jinsman Transit Co. Resumen del Caso 338 E2d 708. Citado por J. M. De LA JARA, G. Rivas y A. JusCAmaita, "Hand vs. Brain: El sesgo de retrospectiva en la implementación de la fórmula de Hand”, en A. Bullard y J. M. De La Jara (Coor.), Análisis Psicológico Del Derecho, pp. 169$181,<$ goo.gl/UahbCG $>$. 
Por otra parte, y de forma adicional a la información antes mencionada, al Grupo Variable se le proporcionó los siguientes hechos futuros:

- La ciudad decidió no contratar un operador del puente.

- Posteriormente, se generó una inundación que causó el desprendimiento del puente, hecho que no hubiera sucedido si hubiera existido un operador.

- La inundación generó daños al negocio de un ciudadano, quien demandó a la ciudad.

Los estudiantes de ambos grupos realizaron un análisis de responsabilidad sobre la conducta de los funcionarios de la ciudad al momento de tomar la decisión de contratar o no el operador del puerto; con la única diferencia relativa al conocimiento de los hechos futuros por parte del grupo Variable.

El estudio arrojó los siguientes resultados: únicamente el 24\% del Grupo de Control (que no contaba con la información sobre los hechos futuros) concluyó que la probabilidad de una inundación justificaba tomar precauciones. Por su parte, dentro del Grupo Variable, el 57\% de los estudiantes determinaron que la inundación era previsible, concluyendo incluso que dicho accidente era tan previsible que el actuar del municipio fue negligente.

El experimento muestra que el conocimiento del desenlace del evento, es decir la realización de un juicio ex-post, necesariamente contamina el análisis ex-ante de las personas. Dicho en otras palabras, al momento de realizar un análisis en retrospectiva, si ya se conoce el resultado, es altamente probable que este conocimiento sesgue y difiera de la forma real en la que se consumaron los hechos en ese momento, evidentemente sin conocimiento de los resultados futuros ${ }^{4}$.

4. Dicho experimento fue replicado por un estudio similar realizado por José María de la Jara a 153 estudiantes de las facultades de derecho de la Pontificia Universidad Católica del Perú, Universidad del Pacífico y Universidad de Piura. El mismo obtuvo resultados similares al experimento de Kamin y Rachlinski con un incremento en los resultados del 13.16\% del Grupo de Control, al 27.55\% del Grupo Variable o prospectivo. Véase, J. M. De La Jara, G. Rivas y A. Juscamaita, N. 3. 
¿Queréis revolución? Hacedla primero en vuestras almas (o en vuestros reglamentos).

Anotaciones sobre posibles reformas reglamentarias al sistema arbitral ecuatoriano

Lo que muestran estos dos experimentos es el sesgo de retrospectiva $a^{5}$. Descrito en palabras de DE LA JARA, "el cerebro tiene la capacidad de transportarnos al pasado, pero la ejecución de esa tarea no implica que olvidaremos lo que ya conocemos del presente [...] el conocimiento del presente es un equipaje obligatorio en cualquier viaje al pasado" 6 . FISCHHOFF, por su parte, establece que

[e]n retrospectiva, las personas constantemente exageran lo que podría haberse anticipado de antemano. No solo tienden a ver lo que sucedió como algo inevitable, sino que consideran que ha sido "relativamente inevitable" antes de que sucediera. La gente cree que los demás debían haber sido capaces de anticipar los acontecimientos mucho mejor de lo que realmente era el caso. Incluso recuerdan mal sus propias predicciones para exagerar en retrospectiva lo que sabían de antemano ${ }^{7}$.

Actualmente, las críticas a la LAM ecuatoriana han sido duras. Coincidimos en que muchas de ellas son bastante fundadas; sin embargo, es preciso manifestar que es innegable que estas críticas se encuentran sesgadas por retrospectiva.

Por ejemplo, actualmente es evidente, al menos para la mayoría del foro arbitral ecuatoriano, que resulta infructuosa la supletoriedad de la norma procesal adjetiva establecida en el artículo 37 de la $\mathrm{LAM}^{8}$. Sin embargo, al voltear a ver al año 1997, época en la que el arbitraje únicamente existía en la literalidad de una norma empolvada expedida en el año 1963 denominada Ley de Arbitraje Comercial", en el título 33 "Juicio por arbitramiento" del Código de Procedimiento Civil (en adelante, CPC) de 1953 y en los casos sustanciados bajo dichas normas, mismos podían ser

5. Al respecto, véase X. Andrade Cadena, C. Arroyo Aguirre y E. Fierro, "Vicios, sesgos y conjuros arbitrales", Revista Ecuatoriana de Arbitraje, No. 8, 2016.

6. Véase J. M. De La Jara, G. Rivas y A. Juscamaita, N. 3, p. 181.

7. Traducción libre. B. FISCHHOFF, Judgment and Decision Making, Earthscan from Routledge, 2012, pp. 335-341.

8. Ley de Arbitraje y Mediación (LAM), Art. 37, RO No. 417, 14/12/2006

Art. 37.- En todo lo que no esté previsto en esta Ley, se aplicarán supletoriamente las normas del Código Civil, Código de Procedimiento Civil o Código de Comercio y otras leyes conexas, siempre que se trate, de arbitraje en derecho.

9. Ley de Arbitraje Comercial, RO No. 90 de 28/10/1963. Ley dictada mediante Decreto Supremo No. 735 de 23/10/1963. 
contados con los dedos de una mano; hace sentido que el legislador haya dado ciertas luces guía, denominadas en aquel momento Código de Procedimiento Civil, para el recién nacido sistema arbitral ecuatoriano.

Durante la última década el arbitraje, a pesar de los arrebatos político-jurídicos que ha padecido, ha generado una considerable institucionalidad. Es por ello que, en este momento, realizando un juicio ex-post, resulta lógico aseverar por ejemplo que, uno de los talones de Aquiles del sistema arbitral, es la supletoriedad de la normativa procesal ordinaria, en su momento el CPC y actualmente el Código Orgánico General de Procesos (en adelante, COGEP); supletoriedad que, además de ser mandato legal, parece ser mandato moral en la mente de varios abogados y árbitros que, en mayor o menor medida, frecuentan el sistema ${ }^{10}$.

$\mathrm{Al}$ respecto CORONEL JONES, menciona que el arbitraje ha enfrentado

[...] dificultades, resistencias y temores, especialmente por parte de los operadores jurídicos: abogados, jueces e inclusive los propios árbitros quienes, formados con las ideas de respeto profundo a las normas procesales, inclusive inclinados hacia el formalismo y ritualismo en la práctica litigiosa, se ven abocados a lidiar con una moralidad de resolución de controversias que privilegia ampliamente el contenido sobre la forma, la agilidad y celeridad por sobre el rito y las fórmulas sacramentales ${ }^{11}$.

El momento político, las críticas a la LAM, en conjunto con ciertas normas obsoletas que contiene, sumados a la profunda inestabilidad generada por la anulación desmesurada de laudos

10. Al respecto J.M. DE LA JARA, en su artículo "El ataque de los procesalosauriso" expresa: "Rondan por las escaleras del Poder Judicial y tienen largas garras con las que amedrentan a secretarios, jueces y congresistas. Su dieta básica consiste en una porción de excepciones, con guarnición de impugnaciones y salsa de formalismo. Que quede claro: no son abogados procesalistas. Se hacen pasar como tales, pero en realidad son litigantes y 'operativos' estancados a la mitad de la cadena evolutiva, sin capacidad de adecuarse a un sistema transparente". J.M. DE LA JARA, "El ataque de los procesalosaurios", en A. Bullard (Ed.), Litigio Arbitral: El Arbitraje Desde Otra Perspectiva, 2016, p. 165.

11. C. Coronel Jones, “Arbitraje y Procedimiento”, Iuris Dictio, Vol. 7, No. 11, 2007, p. 37. 
¿Queréis revolución? Hacedla primero en vuestras almas (o en vuestros reglamentos).

Anotaciones sobre posibles reformas reglamentarias al sistema arbitral ecuatoriano

arbitrales a cargo de los presidentes de las cortes provinciales ${ }^{12}$; ha generado que importantes voces reclamen una reforma a la LAM.

Concordamos: la LAM necesita una reforma urgente; sin embargo, es preciso realizar un mea culpa en este sentido, ya que la misma naturaleza del sistema arbitral nos permite realizar esta reforma, al menos con efectos individuales, de múltiples formas. Ya sea a través del pacto de cláusulas arbitrales que contemplen reglas procesales más sofisticadas, o a través de acuerdos probatorios o procedimentales intraproceso.

Pero las cláusulas arbitrales no pueden regular todo. Es por esta limitación que las reformas deben realizarse principalmente a través de la actualización de los reglamentos de los centros. Es una tarea conjunta que nos compete a todos quienes conformamos el sistema arbitral. En este sentido, DERAINS y LÉVY establecen que "[l]os árbitros son responsables de 'las tuercas y tornillos' del procedimiento, pero el diseño general de dichos procedimientos es un asunto de las partes y sus abogados"13. "[...] [P]ara que el procedimiento arbitral sea adecuado y eficaz, hay conductas y prácticas que dependen de los demás involucrados: abogados, partes y secretario arbitral"14, y los centros a través de sus reglamentos.

Es el artículo 38 de la LAM, el que ubica en nuestra cancha la forma de subsanar la mayoría de los errores ${ }^{15}$ de dicho cuerpo al establecer que:

El arbitraje se sujetará a las normas de procedimiento señaladas en esta Ley, al procedimiento establecido en los centros de arbitraje, al determinado en el convenio arbitral o al que

12. Lo antedicho fue profundizado por O. Santos Dávalos. Véase, O. Santos DÁvalos, "La acción de nulidad de los laudos arbitrales", Revista Ecuatoriana de Arbitraje, No. 8, 2016, p. 401.

13. Y. Derains y L. LÉvy, Is arbitration Only as Good as Arbitrator? Status, Power and Role of the Arbitrator, Dossiers of the ICC Institute of World Business Law, 2011, p. 8.

14. J. E. FiguEROA, "Buenas prácticas para la mejor conducción del procedimiento en el arbitraje comercial internacional”, Revista Ecuatoriana de Arbitraje, No. 7, 2015, p. 341.

15. Mencionamos la mayoría, ya que el único elemento que no podría subsanarse a través de reformas a los reglamentos de los Centros, por encontrarse en la esfera del orden público, son las normas relativas a la acción de nulidad. 
las partes escojan, sin perjuicio de las normas supletorias que sean aplicables ${ }^{16}$.

La norma es contundente. Son las partes, por el principio de autonomía de la voluntad, las encargadas de regular su proceso; entendiendo a los reglamentos de los centros como una delegación de esta autonomía plasmada al momento de pactar un centro específico en la cláusula compromisoria. El principio de autonomía de la voluntad de las partes también se encuentra regulado en el artículo 5 de la LAM, el mismo que guarda concordancia con lo establecido en la Ley Modelo $\mathrm{CNUDMI}^{17}$, así como con lo establecido en la Convención de las Naciones Unidas sobre el Reconocimiento y Ejecución de las Sentencias Arbitrales Extranjeras de 1958 al incluir como causal de denegación de homologación, y por lo tanto de ejecución establecida en el artículo $\mathrm{V}(1)(\mathrm{d})$ el hecho de que "la constitución del tribunal arbitral o el procedimiento arbitral no se han ajustado al acuerdo celebrado entre las partes" 18 .

\section{REFORMAS REGLAMENTARIAS AL SISTEMA ARBITRAL ECUATORIANO}

Acogiéndonos a la afamada frase expresada por el ex presidente ecuatoriano José María Velasco Ibarra - ¿Queréis revolución? ¡Hacedla primero en vuestros corazones y en vuestras almas! - entendemos que las reformas deben partir tanto de los centros arbitrales, como de los abogados, más aún con la oportunidad, otorgada por la naturaleza del sistema arbitral de autorregularse.

16. LAM, N. 8, Art. 38.

17. "Probablemente el principio más importante sobre el que debe basarse la Ley Modelo es la libertad de las partes, para facilitar el adecuado funcionamiento de los arbitrajes comerciales internacionales de acuerdo con sus expectativas". Citado por la Comisión de las Naciones Unidas sobre Derecho Mercantil Internacional (CNUDMI), Report of the Secretary-General on Possible Features of a Model Law on International Commercial Arbitration (A/CN.91207), en XII Yearbook of the United Nations Commission on International Trade Law, 1981, pp. 75-78.

18. Convención de las Naciones Unidas sobre el Reconocimiento y Ejecución de las Sentencias Arbitrales Extranjeras de 1958, Art. V(1)(d), RO Sup. No. 153, 25/11/2005. 
¿Queréis revolución? Hacedla primero en vuestras almas (o en vuestros reglamentos).

Anotaciones sobre posibles reformas reglamentarias al sistema arbitral ecuatoriano

Sin perjuicio de la existencia de otros elementos relevantes que merezcan una reforma, hemos identificado los siguientes elementos de la LAM, que pueden ser subsanados a través de reformas reglamentarias, y sobre los cuales nos referiremos en el presente ensayo: (i) mecanismo de designación del Tribunal Arbitral; (ii) caución en procesos de nulidad; (iii) árbitro de emergencia; (iv) causales de recusación y excusa; (v) prácticas probatorias; (vi) calendario procesal; (vii) citación por la prensa; $\mathrm{y}$, (viii) audiencia de lectura del laudo.

Para la presente investigación se ha realizado un análisis comparativo de los reglamentos de los principales centros de arbitraje a nivel nacional, esto es los Centros CCQ, AMCHAM, CCG, CENAMACO, CPA, CIAM y el Reglamento Modelo de Arbitraje Doméstico del IEA.

\subsection{Mecanismos de designación del Tribunal Arbitral}

La designación de la persona que decidirá el pleito, como vertiente del principio de autonomía de la voluntad de las partes, es uno de los elementos constitutivos del sistema arbitral. Dicho elemento se ve menoscabado cuando la designación se la realiza por un mecanismo que rebasa la voluntad de las partes, como lo es el sorteo.

Si bien es cierto que en principio, la LAM en su artículo 16 reconoce este principio al establecer como primera forma de designación el acuerdo de las partes sobre la totalidad del tribunal arbitral $^{19}$, es preciso recalcar que este mecanismo es ineficaz ya

19. LAM, N. 8, Art. 16.

Art. 16.- De no existir acuerdo total en la audiencia de mediación, el director del centro de arbitraje enviará a las partes la lista de árbitros, para que de común acuerdo designen en el término de tres días los árbitros principales y el alterno que deban integrar el tribunal. Los acuerdos parciales a que arriben las partes en la audiencia de mediación serán aprobados conforme a lo previsto en el artículo anterior. Las partes, de común acuerdo, podrán designar árbitros de fuera de la lista presentada por el respectivo centro. Las partes podrán acordar expresamente y por escrito que sea un solo árbitro el que conozca de la controversia. Este árbitro tendrá su alterno. Si las partes no efectuaren la designación de alguno o varios árbitros o no se pusieren de acuerdo en ella, la designación se hará por sorteo, para lo cual el director del centro de arbitraje notificará a las partes a fin de que, en la fecha y hora que se señale y ante el presidente del centro de arbitraje, se efectúe el sorteo, de cuya diligencia se sentará 
que difícilmente las partes, una vez escalado el conflicto, lograrán acordar en la totalidad de miembros de un tribunal, lo que deviene inevitablemente en que este sea designado por sorteo.

La forma usual de suplir la designación por sorteo, es la establecida por la Ley Modelo CNUDMI, misma que establece básicamente que cada parte designa un árbitro, y el presidente es nombrado de común acuerdo por los árbitros ya designados.

En este sentido, si bien es cierto que la regla general de la LAM en la práctica termina siendo el sorteo, esto puede ser plenamente subsanable por varias formas, ya sea a través de cláusulas compromisorias que contengan mecanismos de designación del tribunal; o a través de reglamentos que reformen el mecanismo preestablecido de la LAM.

De la revisión de los 6 reglamentos referidos anteriormente, se desprende que todos ellos acogen el mecanismo de designación de la LAM; incluso el reglamento del CIAM, se podría entender que evade el envío de la lista de árbitros a las partes y ordena la convocatoria directa al sorteo. El mismo, en su artículo 7 establece:

INTEGRACIÓN DEL TRIBUNAL. - Para la integración del tribunal arbitral, el Director del Centro procederá a identificar la materia del juicio arbitral, con la finalidad de realizar el sorteo entre los árbitros especializados, con conocimientos afines a la materia del juicio en referencia.

A falta de árbitros con conocimientos específicos en la materia del juicio arbitral, se sorteará entre todos los constantes en la lista oficial de árbitros del Centro.

el acta respectiva, quedando en esta forma legalmente integrado el tribunal de arbitraje. En tratándose de arbitraje independiente, las partes designarán en el convenio arbitral al árbitro o árbitros principales $\mathrm{y}$ al alterno que deban integrar el tribunal. Si las partes no se pusieren de acuerdo para nombrar todos los árbitros, los designados, una vez posesionados, nombrarán a los que faltaren. En el evento de que el árbitro o árbitros independientes no aceptaren o no se posesionaren de su cargo y los árbitros posesionados no se pusieren de acuerdo en el nombramiento de los árbitros que faltaren, cualquiera de las partes podrá pedir la designación de éstos al director del centro de arbitraje más cercano al domicilio del actor. Dicha designación se la hará conforme a lo establecido en el presente artículo (énfasis añadido). 
¿Queréis revolución? Hacedla primero en vuestras almas (o en vuestros reglamentos).

Anotaciones sobre posibles reformas reglamentarias al sistema arbitral ecuatoriano

El sorteo de los árbitros se hará con la presencia de las partes procesales, previa convocatoria para la diligencia ${ }^{20}$.

Adicionalmente, es necesario resaltar que varios reglamentos ordenan que el sorteo deberá realizarse en duplicado para cada árbitro ${ }^{21}$, con la finalidad de evitar múltiples convocatorias a sorteos hasta que acepte la totalidad del tribunal arbitral. Dicha práctica es acertada por la celeridad que brinda al proceso.

Al respecto, el Reglamento Modelo del IEA innova en cuanto al mecanismo de designación, acogiendo el establecido por la Ley Modelo CNUDMI. El artículo 10 numeral 5 de dicho reglamento establece:

Salvo acuerdo en contrario de las partes, para la constitución un Tribunal Arbitral con tres árbitros, se observarán las siguientes reglas:

a. El Demandante o Demandantes, en conjunto, designarán en su Demanda su respectivo árbitro.

b. La Demandada o Demandadas, en conjunto, designarán en su Contestación a la Demanda su respectivo árbitro.

c. Una vez aceptados sus cargos, los árbitros designados por las partes, dentro del plazo dispuesto por el Director del CAM, designarán al tercer árbitro que presidirá el Tribunal Arbitral.

d. Si alguna de las partes o los árbitros designados por ellas no designan a los respectivos árbitros, esta designación le realizará el Director del CAM por sorteo de entre los árbitros de las listas del $\mathrm{CAM}^{22}$.

\subsection{Caución}

La LAM es sumamente escueta al regular la caución necesaria para la suspensión en la ejecución del laudo arbitral durante

20. Reglamento del Centro Internacional de Arbitraje y Mediación (CIAM), Art. 7.

21. Véase, Reglamento del Centro de Arbitraje y Mediación de la Cámara de Comercio de Quito (CCQ), Art. 58; Reglamento del Centro de Arbitraje y Mediación de la Cámara de Comercio Ecuatoriano Americana (AMCHAM), Art. 50; y Reglamento del Centro de Arbitraje y Conciliación de la Cámara de Comercio de Guayaquil (CCG), Art. 13.

22. Reglamento Modelo de Arbitraje Doméstico del Instituto Ecuatoriano de Arbitraje (IEA), Art. 10(5). 
la sustanciación de la acción de nulidad. Al respecto, el artículo 31 de la LAM establece como único parámetro que la caución será fijada " [...] sobre los perjuicios estimados que la demora en la ejecución del laudo pueda causarle a la otra parte"2324.

El hecho de que el único parámetro para la determinación del monto de la caución sea la estimación de los perjuicios por la demora en la ejecución del laudo mientras se sustancia el proceso de nulidad, ha generado múltiples vulneraciones de derechos en este aspecto, como el caso GAD Río Verde, sobre el cual volveremos posteriormente. Existe además un vacío sobre la forma en la que esta caución debe instrumentarse y devolverse.

Al respecto vale la pena mencionar el caso GAD Río Verde, dentro del cual el tribunal arbitral no sólo decidió fijar el monto de la caución en el valor de la totalidad del laudo ${ }^{25}$, sino que, ante la falta de consignación de la caución, el tribunal ignorando completamente que el único efecto de la caución es la suspensión en la ejecución del laudo, se negó a remitir la acción de nulidad interpuesta por el demandado a la Corte Provincial ${ }^{26}$.

Justamente para evitar este tipo de abusos, la fijación del valor de la caución debería ser objeto de regulación dentro de los

23. LAM, N. 8, Art. 31.

Art. 31.- [...] Quien interponga la acción de nulidad, podrá solicitar al árbitro o tribunal arbitral que se suspenda la ejecución del laudo, rindiendo caución suficiente sobre los perjuicios estimados que la demora en la ejecución del laudo pueda causar a la otra parte. El árbitro o tribunal arbitral, en el término de tres días, deberán fijar el monto de la caución, disponiendo la suspensión de la ejecución del laudo. La caución deberá constituirse dentro del término de tres días, contados a partir de esta notificación.

24. El COGEP tampoco brinda luces al respecto. El artículo 271 de dicha norma se limita a enmarcar la figura, sin regular la forma de fijación del quantum o su forma de instrumentación.

25. Mediante providencia de 21/12/2017 el tribunal ordenó que: “[...] en el término de 3 días rindan caución suficiente garantizando los daños y perjuicio [sic] que la demora de la ejecución del laudo arbitral pueda causar a la otra parte, el valor de la caución es de USD 459.440,76/100. Tal como lo determina el Art. 31 de la Codificación a la Ley de Arbitraje y Mediación [...]”. Tomado de la presentación realizada por el Dr. Fausto Albuja Guarderas el 16/05/2018 en la CCQ.

26. Mediante Providencia de 23/01/2018, el tribunal arbitral estableció que: “[...] por cuanto los recurrentes, no dieron cumplimiento a lo dispuesto por este tribunal en decreto de 21/12/2017, a las $11 \mathrm{~h} 10$, es decir, no rindieron caución suficiente, por los perjuicios estimados que en la demora de la ejecución del laudo pueda causar a la otra parte contraviniendo la disposición legal prevista en la letra e), inciso cuarto del Artículo 31 de la Ley de Arbitraje y Mediación; y lo dispuesto por la Corte Constitucional del Ecuador, en sentencia No. 007-16-SCM.CC, CASO No. 0141-14-CN, este Tribunal Arbitral amparado en las Normas Legales y Constitucionales citadas; y en el precedente constitucional antedicho, niega los recursos de nulidad, interpuestos por el demandado [...]". Tomado de la presentación realizada por el Dr. Fausto Albuja Guarderas el 16/05/2018 en la CCQ. 
¿Queréis revolución? Hacedla primero en vuestras almas (o en vuestros reglamentos).

Anotaciones sobre posibles reformas reglamentarias al sistema arbitral ecuatoriano

reglamentos de los centros, mismos que, respetando la discrecionalidad del tribunal, otorguen luces al respecto. Ninguno de los siete reglamentos revisados lo regula.

Por otro lado, sobre la falta de regulación de la forma de instrumentación de la caución, y de su devolución, los únicos reglamentos que lo abordan son los pertenecientes al Centro de Arbitraje y Conciliación de la CCG, que en su artículo $26^{27}$ ordena la entrega de la caución "a quién corresponda". Así también, el reglamento AMCHAM, en su artículo 66 establece taxativamente las formas en las que se podrá instrumentar la caución, esto es: (i) Garantía bancaria, (ii) Fianza a través de una aseguradora, y, (iii) Dinero efectivo o cheque ${ }^{28}$. Finalmente, cabe mencionar que el Reglamento Modelo del IEA, recoge ambos criterios, regulando tanto la entrega de la caución, como la forma de su instrumentación en su artículo $37^{29}$.

27. Reglamento del Centro de Arbitraje y Conciliación de la CCG, N. 21, Art. 26.

Art. 26.- Cuando se haya solicitado la suspensión de la ejecución del laudo por haberse interpuesto acción de nulidad, el tribunal fijará la caución teniendo en cuenta los perjuicios estimados que la demora en la ejecución de lo ordenado en el laudo pueda irrogar a la parte vencedora del arbitraje. La caución se constituirá a favor de la Cámara de Comercio de Guayaquil, quien dispondrá su entrega a quien corresponda, una vez ejecutoriada la sentencia que resuelva la acción de nulidad.

28. Reglamento del Centro de Arbitraje y Mediación AMCHAM, N. 21, Art. 66.

Art. 66.- Cuando se haya solicitado la suspensión de la ejecución del laudo por haberse interpuesto acción de nulidad, el tribunal fijará la caución teniendo en cuenta los perjuicios estimados que la demora en la ejecución de lo ordenado en el laudo pueda irrogar a la parte vencedora del arbitraje. Las cauciones que podrán rendirse son: 1. Garantía incondicional, irrevocable y de cobro inmediato, otorgada por un banco, o institución financiera, establecidos en el país o por intermedio de ellos; 2. Fianza instrumentada en una póliza de seguros, incondicional e irrevocable, de cobro inmediato, emitida por una compañía de seguros establecida en el país; 3. Efectivo o Cheque Certificado de una institución financiera establecida en el país consignado en la Cámara de Comercio Ecuatoriano Americana, que deberá ser depositado en una cuenta de la misma. La caución se constituirá a favor del vencedor del arbitraje y se entregará a la Cámara de Comercio Ecuatoriano Americana, quien dispondrá su entrega a quien corresponda, una vez ejecutoriada la sentencia que resuelva la acción de nulidad. La caución rendida deberá ser renovable automáticamente antes de su vencimiento o a la sola solicitud del Centro. De no ser renovada la caución esta se efectivizará y la Cámara tendrá los fondos disponibles hasta cuando se resuelva la acción de nulidad.

29. Reglamento Modelo IEA, N. 22, Art. 37.

Art. 37. - Suspensión de los efectos del laudo. 1. Cuando se haya solicitado la suspensión de la ejecución del laudo por haberse interpuesto acción de nulidad, el tribunal fijará la caución teniendo en cuenta los perjuicios estimados que la demora en la ejecución de lo ordenado en el laudo pueda irrogar a la parte vencedora del arbitraje. 2. Las cauciones que podrán rendirse son: a. Garantía incondicional, irrevocable y de cobro inmediato, otorgada por un banco, o institución financiera, establecidos en el país o por intermedio de ellos; b. Fianza instrumentada en una póliza de seguros, incondicional e irrevocable, de cobro inmediato, emitida por una compañía de seguros establecida en el país; c. Efectivo o Cheque Certificado de una institución financiera establecida en el país consignado en la Cámara XX, que deberá ser depositado en una cuenta de la misma. 3. La caución se constituirá a favor del vencedor del arbitraje y se entregará a la Cámara XX, quien dispondrá su entrega a quien corresponda, una vez ejecutoriada la sentencia que resuelva la acción de nulidad. 4. La caución deberá ser constituida en el 


\section{3 Árbitro de emergencia}

La figura del árbitro de emergencia nace por la necesidad de las partes en un arbitraje de adoptar medidas provisionales urgentes no habiéndose constituido el tribunal arbitral aún. Al no existir en ese momento quien conserve el status quo, preserve la evidencia, proteja bienes e información, entre otros; las partes recurren al árbitro de emergencia. En palabras de BORN y LEE:

El procedimiento del árbitro de emergencia está destinado a conocer situaciones de extrema urgencia, [por lo que,] hace poco sentido forzar a las partes a esperar hasta el comienzo formal del procedimiento arbitral para buscar medidas temporales a través de dicho procedimiento ${ }^{30}$.

Varios centros arbitrales alrededor del mundo han incorporado esta figura en sus reglamentos. Entre esos, están los reglamentos de arbitraje de la Cámara de Comercio Internacional del Centro de Arbitraje Internacional de Singapur, del Centro de Arbitraje Internacional de Hong Kong y del Centro Internacional para la Resolución de Disputas, siendo este último el primero en adoptar reglas sobre la figura.

En vista de la falta de reconocimiento de esta figura tanto en la LAM como en los reglamentos, las partes tendrán que acudir a la justicia ordinaria a pesar de que "[...] acudir al Poder Judicial es justamente lo que se buscó evitar cuando se pactó arbitraje"31. Acudir al poder judicial adicionalmente podría tener un conflicto de competencia, ya que el artículo 120 del COGEP establece que la competencia para el conocimiento de la demanda principal se radica en el juzgador que conoce la diligencia preparatoria. Es

término establecido por el Tribunal Arbitral para estos efectos. Este término podrá ser prorrogado a solicitud motivada de parte. 5. La caución rendida deberá ser renovable automáticamente antes de su vencimiento o a la sola solicitud del Centro. De no ser renovada la caución esta se efectivizará y la Cámara tendrá los fondos disponibles hasta cuando se resuelva la acción de nulidad. 6. Una vez resuelta la acción de nulidad la caución será devuelta: a. Al vencedor del arbitraje, si la acción de nulidad fuera rechazada. b. Al proponente de la acción de nulidad, si la acción de nulidad fuera aceptada, total o parcialmente.

30. G. Born y S. LeE, “The Emergency Arbitrator Procedure under the New HKIAC Rules", Asian Dispute Review, No. 4, pp. 116-117.

31. H. Ezcurra y J. OlóRtegui, "Y ahora, ¿quién podrá defendernos? El árbitro de emergencia", en A. Bullard (Ed.), Litigio Arbitral: El Arbitraje Desde Otra Perspectiva, 2016, pp. 193-194. 
¿Queréis revolución? Hacedla primero en vuestras almas (o en vuestros reglamentos).

Anotaciones sobre posibles reformas reglamentarias al sistema arbitral ecuatoriano

por este motivo que existen múltiples resoluciones de inadmisión argumentando que es competencia exclusiva del tribunal arbitral el conocimiento de diligencias preparatorias.

El reglamento de arbitraje de la Cámara de Comercio Internacional (en adelante, CCI) regula la figura del árbitro de emergencia en su artículo 29 y le dedica un apéndice completo (Apéndice V). Su aplicación supone que no se ha constituido el tribunal arbitral todavía y que adoptar medidas provisionales es de carácter urgente. Es el Presidente de la Corte quien nombra al árbitro de emergencia previa petición de parte, no siendo posible nombrarlo una vez que se ha entregado el expediente al tribunal arbitral. La decisión que adopte el árbitro de emergencia tiene carácter de orden y es vinculante para las partes, pero no para el tribunal arbitral que se constituya, según el artículo 29 del reglamento ICC; ya que, según dicho artículo, el tribunal arbitral tiene la facultad de modificar, dejar sin efecto o anular una orden emitida por el árbitro de emergencia.

Dicha figura no se encuentra regulada ni en la LAM, ni en ninguno de los reglamentos analizados, salvo el Reglamento Modelo del IEA, que, refiriéndose a las medidas provisionales o cautelares, en su artículo 25(2)(b) establece que estas podrán ser solicitadas "ante un árbitro de emergencia conforme al reglamento que el Centro expida para estos fines" ${ }^{32}$.

32. Reglamento Modelo IEA, N. 22, Art. 25.

Art. 25.- Medidas cautelares y provisionales. 1. El Tribunal Arbitral podrá dictar medidas provisionales o cautelares conforme lo establecido en la Ley de Arbitraje y Mediación para asegurar el estado de los bienes objeto del litigio, preservar pruebas, garantizar el resultado del laudo o mantener el status quo de la disputa. 2. Las partes, con los mismos fines anteriores, podrán, antes de la conformación del Tribunal Arbitral y en circunstancias apropiadas, solicitar medidas provisionales o cautelares: a. Ante cualquier autoridad judicial competente. La solicitud que una parte en este sentido no contraviene el convenio arbitral ni constituye una renuncia a éste, y no afecta la competencia y los poderes del Tribunal Arbitral al respecto. Dicha solicitud, así como cualquier medida adoptada por la autoridad judicial, debe ser notificada sin dilación al CAM por la parte solicitante de la misma. b. Ante un árbitro de emergencia conforme al reglamento que el Centro expida para estos fines. 3. Toda medida provisional o cautelar dictada conforme el numeral anterior podrá ser confirmada, revisada, reemplazada o dejada sin efecto por el Tribunal Arbitral. 


\subsection{Recusación y excusa}

La imparcialidad e independencia del juzgador constituye uno de los elementos esenciales del debido proceso ${ }^{33}$. Al respecto, la LAM se limita a remitirse a las causales establecidas en el COGEP $^{34}$, las cuales son: (i) ser parte en el proceso; (ii) ser cónyuge o conviviente en unión de hecho de una de las partes o su abogado; (iii) ser pariente hasta el cuarto grado de consanguinidad o segundo de afinidad de una de las partes o su abogado; (iv) haber conocido o fallado en otra instancia y en el mismo proceso; (v) retardo injustificado; (vi) haber representado a alguna de las partes; (vii) haber emitido opinión o consejo anterior sobre el proceso; (viii) existencia de un proceso anterior con alguna de las partes; (ix) haber recibido de las partes derechos, contribuciones, bienes, valores o servicios; $(\mathbf{x})$ tener con las partes o sus defensores alguna obligación pendiente; (xi) amistad íntima o enemistad manifiesta; $y$, (xii) tener interés personal en el proceso ${ }^{35}$.

Resulta evidentemente impropia la aplicación irrestricta en el arbitraje de una normativa descontextualizada de este método alternativo $^{36}$. Al respecto, GALINDO y GARCÍA manifiestan que

pareciese que es impropio a la naturaleza del arbitraje establecer una valoración abstracta y a priori de estas circunstancias, presumiendo que ellas entrañan una falta de imparcialidad e independencia de los árbitros per se, sin

33. Constitución de la República del Ecuador, Art. 76(7)(k), RO No. 449, 20/10/2008.

Art. $76(7)(\mathrm{k})$. - En todo proceso en el que se determinen derechos y obligaciones de cualquier orden, se asegurará el derecho al debido proceso que incluirá las siguientes garantías básicas: [...] 7. El derecho de las personas a la defensa incluirá las siguientes garantías: [...] k) Ser juzgado por una jueza o juez independiente, imparcial y competente [...].

34. LAM, N. 8, Art. 21.

Art. 21.- Son causas de recusación de los árbitros las previstas en el Código Orgánico General de Procesos para los jueces.

35. Véase, Código Orgánico General de Procesos (COGEP), Art. 22, RO Sup. No. 506, 22/05/2015.

36. Al respecto resulta interesante la resolución de la Directora del Centro de Arbitraje y Mediación AMCHAM dentro de la recusación planteada en el proceso arbitral No. 4-13 en contra de los árbitros Patrick Barrera Sweeney, Alfredo Corral Borrero y Sasha Mandakovic Falconí que establece: “[...] a esta Dirección le resulta al menos difícil de concebir cómo esta causal puede ser aplicable dentro de un proceso arbitral [...]. Un supuesto fenecimiento del encargo arbitral [por vencimiento del término para dictar el laudo] difícilmente podría producir la recusación del [árbitro], pues su efecto se acerca más a la pérdida de la calidad de árbitro [...]”. Citado por E. CARMigniani, H. García y C. Cepeda, “Arbitraje en Ecuador: Desarrollo Jurisprudencial y Reformas Legales Recientes", Revista Ecuatoriana de Arbitraje, No. 7, 2015, pp. 165-194. 
¿Queréis revolución? Hacedla primero en vuestras almas (o en vuestros reglamentos).

Anotaciones sobre posibles reformas reglamentarias al sistema arbitral ecuatoriano

tener debida cuenta de los hechos específicos del caso en particular ${ }^{37}$.

En este aspecto, dentro de la práctica arbitral internacional, ha tenido una importante acogida las Directrices de la International Bar Association (IBA) sobre Conflicto de Intereses. Ninguno de los reglamentos analizados en el presente artículo contempla explícitamente ${ }^{38}$ la posibilidad de recurrir a las dichas Directrices; sin embargo, es preciso manifestar que han sido objeto de referencia de varios fallos de recusación.

En la recusación sustanciada en contra del árbitro Santiago Cuesta Cauputi, dentro del caso Chaparro c. Ecuador, el tribunal se cuestiona:

¿[D]entro del nuevo marco constitucional del Ecuador, la defensa de este principio se agota en la aplicación lex dura, sed lex de estas causales, o es menester revisar las circunstancias particulares de cada caso?.- [...] Parece ser entonces que una aplicación fría y estática de la norma procesal sobre la recusación a la luz de las disposiciones citadas, debe ser soslayada a favor de un verdadero examen de las circunstancias del caso propio, con el fin de verificar la imparcialidad e independencia del juzgador; por lo tanto, al analizar la causal acusada no solo es obligación de este tribunal realizar una interpretación puramente exegética sino también un análisis de la situación fáctica descrita por el legislador, con el fin de garantizar los principios y garantías ya enunciados ${ }^{39}$.

Posteriormente el Tribunal hace referencia a las Directrices de la IBA estableciendo que

[t]odos estos conceptos coincidentes han sido recogidos de manera muy prolija por las Directrices de la International Bar

37. A. Galindo y H. García, "Relación entre el Código Orgánico General de Procesos y el procedimiento arbitral", Revista Ecuatoriana de Arbitraje, No. 6, 2014, p. 51.

38. Referimos explícitamente, ya que existen varios reglamentos que facultan en casos de oscuridad en el reglamento, esta puede ser suplida por normas de otros reglamentos, o en este caso por las Directrices. Véase, Reglamento del Centro de Arbitraje y Mediación CCQ, N. 21, Art. 91; Reglamento del Centro de Arbitraje y Mediación AMCHAM, N. 21, Art. 107, Reglamento Modelo IEA, N. 22, Art. 42.

39. Tribunal Arbitral ad-hoc, Chaparro Álvarez c. Ecuador: Laudo final y Recusación de Santiago Cuesta, en H. GARCÍA, Gaceta arbitral, No. 1, 2013. Citado por A. GALINDO y H. GARCíA, N. 37, pp. 194-195. 
Association (en adelante IBA) sobre conflictos de intereses en el arbitraje internacional, que constituye el catálogo de normas generales y casuística referencial más completo, de mayor aceptación y más usado en la comunidad actual del arbitraje. Estas normas han sido cruciales para el desarrollo del arbitraje, puesto que proponen un test que de manera relativamente objetiva, aterriza el análisis subjetivo que puede inmiscuirse dentro de la imparcialidad e independencia de los árbitros ${ }^{40}$.

Así también las Directrices IBA sobre conflicto de intereses han sido referidas en otros procesos de recusación, como la resolución de la Directora del Centro de Arbitraje y Mediación AMCHAM, Patricia Vera Nieto, dentro de la recusación planteada en el proceso arbitral No. 6-16 en contra del árbitro Alvaro Galindo Cardona ${ }^{41}$.

En este sentido, creemos importante que los reglamentos arbitrales contemplen la posibilidad de someterse, al menos de forma referencial, a las mencionadas Directrices. Ninguno de los reglamentos analizados lo contempla, salvo el Reglamento Modelo del IEA, que en su artículo 12 establece

Para la resolución de las recusaciones planteadas en contra de uno o más árbitros se podrá utilizar de manera referencial las Directrices de la IBA sobre los Conflictos de Intereses en el Arbitraje Internacional, o cualquier otra regla o práctica arbitral relevante ${ }^{42}$.

40. Ibídem.

41. Al respecto, mediante decisión de 3/08/2016, la Directora estableció: "Asimismo, a modo referencial, las Directrices IBA sobre Conflictos de Intereses en Arbitraje Internacional en el numeral 3.1.2 de su Listado Naranja establece como parámetro la revelación que debe hacer el árbitro a las partes cuando: 'Dentro de los tres años anteriores el árbitro fue abogado de una de las partes o de una filial de éstas en un asunto independiente de la causa'. En este sentido es importante recalcar que el Listado Naranja refleja situaciones que pudieran crear dudas acerca de la imparcialidad del árbitro, por lo que se configura la obligación de revelarlas, sin que esto genere necesariamente un conflicto de interés. En relación a lo anterior, la norma citada por la Actora en su solicitud establece un término de tres años, mismo que no se cumple en el presente caso". Citado en E. Carmigniani, H. García y C. Cepeda, N. 36, p. 197.

42. Reglamento Modelo IEA, N. 22, Art. 12(7). 
¿Queréis revolución? Hacedla primero en vuestras almas (o en vuestros reglamentos).

Anotaciones sobre posibles reformas reglamentarias al sistema arbitral ecuatoriano

\subsection{Otras consideraciones}

Finalmente, existen algunos elementos puntuales a resaltar mismos que, por la naturaleza no monográfica del presente ensayo, nos resulta imposible abordar a profundidad; sin embargo, consideramos importante al menos enunciarlas.

\subsubsection{Prácticas probatorias}

Del mismo modo que las Directrices IBA sobre Conflicto de Intereses han adquirido relevancia en el espectro internacional del arbitraje, las Directrices de dicho organismo sobre la práctica de la prueba han marcado, sin lugar a dudas, las mejores prácticas en este sentido. Es por ello que resulta importante que los reglamentos de los centros las incorporen, al menos como una posibilidad para que las partes se acojan a dichas directrices. Ninguno de los reglamentos las consideran, salvo el Reglamento Modelo del IEA que, en su artículo 23 establece:

Salvo acuerdo en contrario, las partes, al presentar la demanda, reconvención o sus respectivas contestaciones, podrán adjuntar peritajes de parte o declaraciones escritas y anticipadas de testigos, para lo cual podrán guiarse por las Reglas de la IBA sobre la práctica de la prueba en arbitraje internacional o cualquier otra regla o práctica arbitral relevante $^{43}$.

\subsubsection{Calendario procesal}

Un calendario procesal emitido al inicio de la etapa arbitral facilita enormemente la conducción ordenada y ágil del procedimiento. Al respecto GONZÁLEZ DE Cossío menciona que "[e]s recomendable por su utilidad, la predictibilidad y facilidad que brinda el organizar para el futuro las etapas y tiempos del procedimiento" ${ }^{\prime 4}$.

43. Reglamento Modelo IEA, N. 22, Art. 23(6).

44. F. GonZÁlez DE Cossío, Arbitraje, 1era Ed., 2014, p. 633. 
Dicho calendario suele constar en un Acta de Misión. De la revisión de los reglamentos, resalta que únicamente se encuentra regulada en el reglamento de la CCG, mismo que, en su artículo 21 establece como elemento que debe contener el acta de misión lo siguiente:

5) [E]l calendario provisional que pretenda seguirse en el arbitraje; $y$,

6) [L]as reglas de procedimiento que va a seguir el tribunal, sin perjuicio de su facultad de determinar reglas específicas posteriormente, en casos o temas determinados ${ }^{45}$.

Así también el Reglamento Modelo de IEA, establece, como parte de los elementos que deberá contener el acta de audiencia de sustanciación: " 1 . El calendario procesal del arbitraje para la presentación de escritos, práctica de prueba y realización de audiencias" ${ }^{\prime 46}$.

\subsubsection{Citación por la prensa (declaración juramentada)}

El COGEP generó un vacío jurídico referente a la citación por la prensa en sede arbitral, ya que, en su artículo 56 establece que la declaración juramentada relativa a la imposibilidad de determinación de la individualidad, domicilio o residencia del demandado debe realizarse ante el juzgador de la causa, ya no únicamente a través de una declaración juramentada como lo establecía el derogado Código de Procedimiento Civil ${ }^{47}$.

Toda vez que, en el proceso arbitral, el juzgador del proceso no existe al momento de la citación, ya que el tribunal arbitral será designado en una etapa posterior, surge la duda sobre la autoridad que debe encargarse de recibir dicho juramento. ¿Debe ser el director del centro, ya que ejerce competencia dentro de la

45. Reglamento del Centro de Arbitraje y Conciliación CCG, N. 21, Art. 21(5)(6).

46. Reglamento Modelo IEA, N. 22, Art.19(7)(1). Véase, Reglamento de Arbitraje de la CCI, Art. 18(4).

47. Código de Procedimiento Civil, Art. 86, RO Sup. No. 687, 18/07/1987.

Art. 86. - [...] La afirmación de que es imposible determinar la individualidad o residencia de quien deba ser citado, la hará el solicitante bajo juramento sin el cumplimiento de cuyo requisito, el juez no admitirá la solicitud [...]. 
¿Queréis revolución? Hacedla primero en vuestras almas (o en vuestros reglamentos).

Anotaciones sobre posibles reformas reglamentarias al sistema arbitral ecuatoriano

etapa pre arbitral, debe ser un notario o debe ser un juez ordinario?

Al respecto consideramos que este vacío debe ser suplido por una norma reglamentaria, inexistente en los reglamentos analizados, salvo el Reglamento Modelo del IEA que lo subsana aclarando que la declaración se la debe realizar ante un notario público $^{48}$.

\subsubsection{Renuncia a la audiencia de lectura del laudo}

Sin lugar a dudas, uno de los ritualismos innecesarios que contiene la LAM es la audiencia de lectura del laudo contemplada en el artículo 29 de dicha norma. En vista de la falta de una finalidad jurídica o práctica relevante, esta audiencia debe ser eliminada, ordenando únicamente la notificación del laudo escrito, como lo es en la práctica internacional. Al respecto vale la pena recalcar que esta audiencia fue eliminada en el Reglamento Modelo del IEA, que en su artículo 28 establece:

Salvo acuerdo en contrario, el laudo será notificado únicamente por escrito, renunciando a que sea leído en audiencia conforme lo dispone el Artículo 29 de la Ley de Arbitraje y Mediación ${ }^{49}$.

Finalmente es preciso mencionar que nos encontramos conscientes que existen múltiples elementos no mencionados que merecen al menos ser debatidos a la luz de una reforma reglamentaria; como lo es la eliminación de la etapa de mediación, la posibilidad de un mecanismo de apelación en la misma sede arbitral, la inclusión de terceros no signatarios, los contratos coligados, entre múltiples otras. Invitamos al análisis de los mis-

48. Reglamento Modelo IEA, N. 22, Art. 3(7).

Art. 3. - Citación y notificaciones. 7. Si al Actor le fuere imposible determinar el domicilio del demandado, deberá presentar una declaración juramentada realizada ante un notario. En tal caso, la citación se realizará mediante dos publicaciones en un diario de amplia circulación en el lugar donde se sigue el arbitraje y del domicilio del demandado, si fuere distinto. El costo de las publicaciones correrá a cargo del interesado.

49. Reglamento Modelo IEA, N. 22, Art. 28(5). 
mos para que sea desde la academia de donde surja la necesidad de actualización reglamentaria y legal.

\section{Conclusiones}

Después de haberse cumplido dos décadas desde la entrada en vigencia de la LAM, queda claro que es momento oportuno para que el sistema arbitral ecuatoriano sea reformado con miras a buscar procesos arbitrales más céleres, eficientes, seguros y económicos.

Queda claro también que existen zonas normativas en las que la voluntad de las partes no alcanza a reformar, como lo son por ejemplo la legislación relativa a la acción de nulidad, sus causales y su trámite, así como aquellas que regulan la homologación y ejecución de laudos arbitrales internacionales; sobre los cuales coincidimos con la necesidad de una reforma a la LAM.

Sin embargo, también existe una gran cantidad de espacios que pueden ser subsanados y autorregulados por el mismo sistema. La actualización del sistema arbitral ecuatoriano, debe comenzar puertas adentro. Esta es una tarea compartida, primeramente, por los abogados al momento de la redacción de cláusulas arbitrales y posteriormente por los centros de arbitraje a través de la actualización de sus reglamentos.

El presente ensayo buscó justamente generar la necesidad de dicha actualización reglamentaria, a través de una enunciación que, lejos de ser taxativa y cerrada, pretende enumerar elementos que a nuestro criterio son perfectamente perfectibles simplemente a través de reformas en los reglamentos de los centros. 